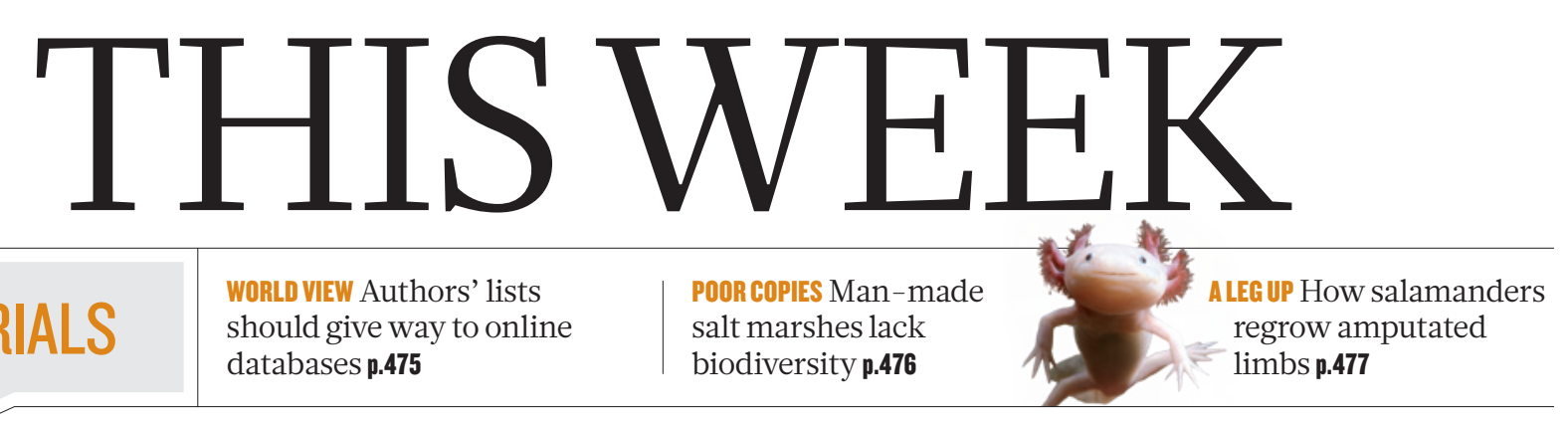

\title{
A second wind for the president
}

\section{A lack of leadership has hampered progress against global warming. If Barack Obama earns a second term as US president, will he have the energy to tackle climate?}

$\mathrm{B}$ arack Obama entered the White House on a wave of hope that was every bit as real for scientists as for voters. Early optimism gave way before often-nasty political realities, but Obama mostly made good on his promises by appointing top-flight researchers to his administration, elevating science within federal agencies and making research and development the foundation of a broader vision of innovation. As he makes his pitch for another four years, there can be little doubt that he intends to continue supporting science. But the vision that he laid out four years ago remains a work in progress.

Nowhere is this clearer than with energy and climate. As discussed on page 488 , the president has increased investments in research and development that may one day help to reduce the cost of clean energy technologies and hasten progress on fighting global warming. Regulations that aim to clean up the atmosphere and protect public health are already encouraging a transition towards cleaner energy. Obama also deserves credit for staking out a centrist position on energy issues, leaving room for both renewables and the smart development of domestic fossil-fuel resources. But as the political discussion about climate has degenerated to a frightening degree during the past four years, he has offered too little leadership on these issues.

The polarization has its roots in both the politics of the economic crisis and the dearth of quick, cheap solutions. Curbing emissions on the scale required to avert dangerous warming is a daunting challenge, but it is feasible and will be cost-effective in the long term. Shifting to cleaner energy would bring benefits not just to climate, but also to air quality, infrastructure and public health. But the cleanest sources of power cost more up front, and politicians are loath to increase energy prices when the economy is struggling. And although the number of green-energy jobs is increasing, shutting down old coal-fired power plants means job losses - and political protests - on a local scale. This has fuelled angry opposition to the modest pollution regulations that Obama's administration has rolled out during his first term.

Given the toxic political atmosphere surrounding the November elections, it is perhaps understandable that the administration, Democrats and even some environmentalists are saying little about global warming. But by failing to speak out, they have often ceded the airwaves to deniers. Although polling shows that almost two-thirds of US citizens support some kind of action on global warming, law-makers in Washington DC are back to debating the validity of climate science. The United States needs leadership that is willing and able to uphold and act on the science.

If Obama wins a second term, he will need to take on the political opposition and bring apparently disparate interests together. This means laying out a clear vision for the future, and making the immediate steps clear. Fortunately, Obama might find it easier to do this during a second term, when he would be free

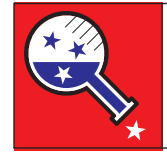

US ELECTION nature.com/election2012 Science and Politics in America to think about his legacy instead of about re-election.

His opponent, Mitt Romney, has a record on global warming that is spotty at best. As governor of Massachusetts from 2003 to 2007, Romney initially supported, then backed out of, the Regional Greenhouse Gas Initiative, a cap-and-trade programme to reduce emissions from electricity generation across New England. Last year, he broke with Republican ranks and declared global warming a threat, but more recently he
"The United

States needs leadership that is willing and able to uphold and act on climate science." has questioned its severity. He is now proposing to roll back the government's regulatory powers. If he wins the election, scientists will have to work with the new administration and hope that the president will muster the courage to take on his own party and govern as the centrist he was in Massachusetts, where he introduced a state health-care initiative that was the model for Obama's national effort.

The next round of greenhouse-gas policies is likely to consist of targeted measures, unlike the economy-wide capand-trade approach that failed in 2010. The Obama administration has regulated emissions from vehicles and required sharp increases in fuel economy; the next big target is electricity generation. Like the car industry, utility companies want economic certainty. Environmentalists want emissions reductions. Is there a way to ensure both without over-burdening consumers? Or could a carbon tax make a comeback as a way to increase revenues and lower income taxes?

Whatever the next steps, they will require bringing the business community together with scientists, environmentalists, workers and others. A clever leader might yet be able to build support for viable political solutions where seemingly narrow interests converge.

\section{Therapy deficit}

\author{
Studies to enhance psychological treatments \\ are scandalously under-supported.
}

$\mathrm{D}$ epression takes many forms, and it is not always easy to diagnose. There is no doubt, however, that it represents a colossal health burden. According to the World Health Organization, it is one of the leading illnesses when ranked by impact on productivity, and directly affects 121 million people worldwide.

As has been discussed in Nature's pages, the standard research-based model of therapy development for psychiatric disorders - target identification, drug discovery and clinical investigation - is imploding as biologists grapple with the complexities and drug companies see too 
few prospects to keep investing. Most psychologists agree that the drugs already in use are efficacious to a point, but with plenty of room for improving their effectiveness and reducing side effects.

Psychological treatments are the other arm of therapy for depression and many psychiatric disorders. The literature is full of trials indicating that they are in some contexts more effective and better at preventing relapse than pharmaceutical interventions. There are no physical side effects, but some of the best-validated treatments depend on therapists with training. Unlike drug therapies, there are no multibillion-dollar suppliers of these treatments with the motivation to market them and make them easily obtainable.

The money being spent on researching psychological therapies is tiny by comparison with budgets for fundamental neuroscience and for translation and drug discovery. And yet such therapies have the potential to make a substantive difference to new categories of patients. What is more, treatments could doubtless be improved in their existing applications by deeper investigation of their outcomes.

This fundamental funding imbalance is compounded by the fact that the sources of research funding disfavour studies of psychological treatments that focus only on efficacy. Nature would be the last to question the importance of research for causal or mechanistic insights. But the brain's complexity and relative inaccessibility leaves a gulf between the current basic understanding and the observed pathologies of human minds. Taking existing psychological therapies and improving and extending their psychological models and applications, and developing new ones, regardless of the underlying neural processes in the brain, is also a justifiable endeavour for funding agencies. Given the immediate benefits this research could bring, the deficit of interest in funding it is a scandal.
Take one prominent example. Since 2006, UK governments have increasingly committed to a programme called Improving Access to Psychological Therapies. This massive, enlightened initiative in psychotherapeutic capacity-building has increased the number of practising cognitive behavioural therapists by several thousand, providing more than 600,000 people with access to these services, particularly patients with depression and anxiety disorders.

\section{"Psychological therapies have the potential to make a substantive difference to patients."}

Inspect the databases of this programme and you find large variations in outcomes between UK regions. A deeper look would allow one to examine many factors relating to the effectiveness of such treatments, thereby opening the prospect of improvements in the United Kingdom and elsewhere.

As psychologists outside Britain will confirm, despite the variability in outcomes, this programme represents a world-beating standard thanks to the scale of its implementation and the validation of its treatments by the UK National Institute for Health and Clinical Excellence. And yet since its inception, the UK government has prevented any of the funds from being used for scientific research on the factors underlying its measured impacts.

This is an extreme example. Many funding agencies around the world are too keen solely to support mechanistic investigations with potential long-term payoffs, and too unwilling to appreciate that part of their portfolio should be oriented towards identifying immediately effective psychological interventions. Success in this area would further encourage policy-makers to enhance much-needed access to treatment for psychiatrically ill individuals. After all, many of these people are taxpayers who ultimately fund research into brains and minds.

\section{Poison postures}

\section{Researchers working on controversial topics must take care how they promote their results.}

"Y es, GMOs are poisons," screamed the front cover of last week's issue of the respectable French news weekly, Le Nouvel Observateur. The blatantly fallacious headline was the opening salvo in a blitz of media coverage about research published online in the journal Food and Chemical Toxicology. The paper, from a research group led by Gilles-Eric Séralini, a molecular biologist at the University of Caen in France, claimed to show that consumption of a genetically modified (GM) maize (corn) that had already been approved for animal and human consumption and of the herbicide Roundup greatly elevates rates of cancer and other illnesses, and causes premature deaths, in rats.

With such strong claims and the predictably large effect they will have on public opinion, researchers should take care how they present their findings to the public and the media. They should spell out their results clearly; emphasize the limitations and caveats; and make it clear that the data still need to be assessed, and replicated, by the scientific community.

That didn't happen. The paper was promoted in a public-relations offensive, with a related book and film set for release this week. Furthermore, journalists wishing to report the research had to sign confidentiality agreements that prevented them from contacting other scientists for comment on the paper until after the embargo had expired. Some, to their credit, refused, or accepted and then revisited the story critically once their hands were no longer tied by these outrageous restrictions.

The result was the exclusion of critical comment in many of the breaking stories - the ones that most people will remember. But much criticism has followed (see page 484). In hindsight, journalists who agreed to the conditions should have contacted the journal publisher
— in this case, Elsevier — which no doubt would have done its best to have made the paper available under embargo without such constraints.

The embargo system gives journalists advance access to papers on the premise that it will give them time to research the story fully before presenting it to the public. The system also benefits journals and authors because it helps to maximize press coverage, but at its heart, it is about helping to improve the quality of science reporting. Crucially, the embargo system allows journalists to consult scientists not involved in the work before interpreting it for the public.

The criticisms that followed questioned both the study's methodology and findings. Given its exceptional claims, the authors of the paper now need to make their raw data available so that they can be carefully assessed by scientists with appropriate expertise, and the work replicated or refuted - thus will the study stand or fall. The European Food Safety Agency, and other advisory and regulatory bodies, are planning to assess the research, and these assessments should be as transparent as possible, so that the public can be confident about whatever they conclude.

The events of last week also illustrate a long-standing flaw in the debate over the safety of GM crops. Many have used last week's publication to claim that GM foods are a health risk. But even if one GM crop were to be shown to have serious adverse health effects, that would say little about others: the safety of any genetic modification depends on the crop and on the particular changes introduced. Scientists who support transgenic crops fall into the same trap when they claim that the many GM crops that have passed safety tests somehow show that 'GMOs are safe.' They should instead be giving the message that GM foods must be assessed on a case-by-case basis.

Too often in the GM-food debate, generalizations and extremism lead to sterile public and political discourse that obscures key issues: what sorts of GM crops might bring true benefits to agriculture and $\rightarrow$ NATURE.COM To comment online, click on Editorials at: go.nature.com/xhunqv consumers; how to avoid monopolization of farming choices; and what types of sustainable agriculture we want in the future. Polarized debates, not GMOs, are the poison to be avoided. $\square$ 